\title{
The Effect of Exercise Therapy on Physical Function, Biochemistry and Dialysis Adequacy in Haemodialysis Patients: A Systematic Review and Meta-Analysis
}

\author{
Neil Smart ${ }^{1 *}$, James McFarlane ${ }^{1}$, Veronique Cornelissen ${ }^{2}$ \\ ${ }^{1}$ Department of Exercise Science, University of New England, Armidale, Australia \\ ${ }^{2}$ Department of Rehabilitation Sciences, University of Leuven, Leuven, Belgium \\ Email: ${ }^{*}$ smart2@une.edu.au
}

Received December 28, 2012; revised February 4, 2013; accepted March 10, 2013

\begin{abstract}
Background: Patients undergoing dialysis have high mortality rates and a unique risk factor profile. Some improvements elicited by exercise training have been shown in dialysis populations, here we aimed to further explore the benefits of exercise. As well as changes in physical fitness we quantified cardiac function, depression, serum biochemistry, dialysis adequacy and energy intake following exercise training in people with chronic kidney disease (CKD) undertaking dialysis. Methods: A systematic literature search was completed in December 2012 identifying randomized, controlled trials of exercise training studies in haemodialysis (HD) patients. A subsequent meta-analysis was conducted. Results: Twenty four studies were included, totalling 879 patients. Exercise training produced significant improvements in physical fitness: peak $\mathrm{VO}_{2} 5.03 \mathrm{mlO}{ }_{2} \cdot \mathrm{kg}^{-1} \cdot \mathrm{min}^{-1}(95 \% \mathrm{CI} 3.73,6.33, \mathrm{p}<0.0001)$, Knee extensor strength 2.99 $\mathrm{kg}(95 \%$ CI $0.46,5.52, \mathrm{p}=0.02)$ and 6 minute walk distance 60.7 metres $(95 \%$ CI 18.9, 103, $\mathrm{p}=0.004)$. Significant increases in energy intake MD $238 \mathrm{Kcal} \cdot \mathrm{day}^{-1}(95 \% \mathrm{CI} 94,383, \mathrm{p}=0.001)$, serum Interleukin-6 MD $-0.58 \mathrm{pg} \cdot \mathrm{ml}^{-1}$ $(95 \% \mathrm{CI}-1.01,-0.15, \mathrm{p}=0.008)$ and C-reactive protein MD $0.92 \mathrm{mg} / \mathrm{L}^{-1}(95 \% \mathrm{CI} 0.29,1.56, \mathrm{p}=0.004)$, but not Albumin or BMI, were reported. Improved Beck Depression scores were reported MD -6.9 (95\% CI -9.7, $-4.1, \mathrm{p}<$ $0.00001)$. Dialysis adequacy was reduced MD $-0.23(95 \% \mathrm{CI}-0.29,-0.17, \mathrm{p}<0.00001)$, while serum potassium was higher MD $0.14 \mathrm{mmol} \cdot \mathrm{L}^{-1}(95 \%$ CI $0.01,0.27, \mathrm{p}=0.04)$. Moreover exercise training appeared safe, with no direct exercise- associated deaths in over 30,000 patient-hours. Conclusions: Our pooled analyses confirmed improvements in physical fitness following exercise training and suggested additional improvements in dialysis efficiency $(\mathrm{kt} / \mathrm{v})$, serum potassium, inflammation and depression in HD patients.
\end{abstract}

Keywords: Exercise Training; Haemodialysis; Meta-Analysis; Systematic Review

\section{Introduction}

Numerous trials have extolled the benefits of exercise training to chronic kidney disease (CKD) patients [1-3]. Common benefits often associated with exercise training are improved peak $\mathrm{VO}_{2}$ [4], quality of life [5], cardiac function [6] and reduced sympatho-adrenal activity [7]. Reduced peak $\mathrm{VO}_{2}$ and poor quality of life have been associated with increased mortality risk in HD patients [8]. Systematic reviews of exercise training have been completed previously but the common focus has been mainly on cardio-respiratory fitness and muscle strength $[1,9,10]$.

The publication of several recent exercise training studies in HD patients prompted our group to conduct the first data pooling analyses to examine if exercise training can also improve dialysis adequacy, depression, body

\footnotetext{
Corresponding author.
}

mass index, serum inflammatory markers, erythropoietin use and several biochemical markers vital to HD patient monitoring. Our analysis further sought to determine if any of these outcome measures, exercise adherence and safety can be optimized with a particular delivery method, e.g. program duration or modality of exercise training.

\section{Methods}

A systematic literature search was completed in December 2012 and subsequent meta-analysis undertaken.

\subsection{Search Strategy}

Potential studies were identified by a systematic search of Medline (Ovid) (1950-December 2012), Embase.com (1974-December 2012), Cochrane Central Register of Controlled Trials and CINAHL (1981-December 2012). 
The search strategy included a mix of MeSH and free text terms for the search terms chronic renal failure, chronic kidney disease, hemodialysis and exercise training, aerobic exercise, resistance exercise, physical activity, strength training and these were combined with a sensitive search strategy to identify randomized controlled trials. Reference list of papers found were scrutinized for new references. All identified papers were assessed independently by two reviewers (NS and JM) and a consensus reached. Searches of published papers were conducted up until December 3rd 2012.

\subsection{Inclusions}

Randomized, controlled trials of exercise training in adult $(>18$ years) chronic kidney disease patients receiving dialysis were included. Included studies reported the post-training mean and standard deviation (SD) or standard error (SE) in exercise and control group of at least one primary or secondary outcome measure (listed below). There were no language restrictions. Acute exercise response studies were not included.

\subsection{Exclusions}

Animal studies, review papers and non-randomized controlled trials were excluded. Studies that did not have an exercise intervention, desired outcome measures, participants who were not chronic kidney disease patients or not receiving dialysis in either treatment or control groups were also excluded. Authors were contacted to provide missing data or clarify if information was duplicated in multiple publications from the same authors. At the time of submission no additional data was forthcoming. Incomplete data or data from an already included study resulted in exclusion.

\subsection{Data Synthesis}

Data relating to chronic kidney disease patient characteristics and exercise training protocols were reviewed. Information was archived in a database and separated into studies that recruited patients undertaking dialysis. Where studies randomized patients to more than two groups only exercise training versus usual care (CKD versus control) data was analyzed. When reviewers suspected data had been duplicated between studies, only study data from the largest patient cohort was analysed.

Outcome measures were peak $\mathrm{VO}_{2}, 6$ minute walk distance, knee extensor strength, cardiac function (left ventricular ejection \%), left ventricular mass index, serum albumin and potassium, inflammatory markers (serum interleukin-6, C-reactive protein), quality of life (SF-36, Beck Depression score), daily energy intake, dialysis adequacy index $(\mathrm{Kt} / \mathrm{v})$ and body mass index.
Data on exercise adherence and safety (number of adverse events were also collected. Measures of study quality were assessed by Jadad score which examined details of randomization, investigator blinding and study withdrawal [11].

\subsection{Statistical Analysis}

For continuous data, we took the approach of assuming randomization would adjust for baseline imbalance and used end-point data only as advised by the Cochrane Collaboration [12]. A random effects inverse variance was used with the effects measure of mean difference (MD). For dichotomous data Mantel-Haenszel fixed effects odds ratio was calculated. Heterogeneity was quantified using a Cochran Q test [13]. We conducted two sub-group analyses; first we compared home versus outpatient exercise training and second we compared those studies of 6 months or greater versus those less than 6 months. We used a $5 \%$ level of significance and $95 \%$ confidence interval, figures were produced by Review Manager version 5.0.

\section{Results}

\subsection{Studies Included in the Review}

Forty-nine randomized controlled trials were identified. Twenty five studies were excluded, leaving 24 full manuscripts. Included studies can be seen in Table 1. Assessment of study quality can be seen in Table 2 . Reasons for study exclusion are seen in Table 3.

Twenty four studies yielding data on 879 HD patients, 493 were exercising participants and sedentary 386 controls. Generally exercise and control groups were well matched at baseline for age, gender, EPO use and peak $\mathrm{VO}_{2}$. Data available from 24 studies of HD patients suggested mean time of receiving haemodialysis was 4.8 (exercise) and 4.5 years (control) and both exercise and control participants demonstrated a mean of two other co-morbid chronic diseases.

\subsection{Peak $\mathrm{VO}_{2}$}

Nine studies (one study examined two types of exercise, hence 10 datasets in Figure 1) [4,6,7,14-19] measured peak $\mathrm{VO}_{2}$ in 400 patients. Significantly greater posttraining peak $\mathrm{VO}_{2}$ values $\left[+5.03 \mathrm{mlO}_{2} \cdot \mathrm{kg}^{-1} \cdot \mathrm{min}^{-1}(95 \%\right.$ CI $3.73 ; 6.33, \mathrm{p}<0.00001)]$ were exhibited following exercise versus control (Figure 1). Mean post-intervention peak $\mathrm{VO}_{2}$ for both exercise and control participants were $23.1 \pm 2.6$ and $18.1 \pm 3.3 \mathrm{mlO}_{2} \cdot \mathrm{kg}^{-1} \cdot \mathrm{min}^{-1}$ respectively.

\subsection{Effect of Exercise Training Duration}

A further analysis was conducted to examine the effect of 


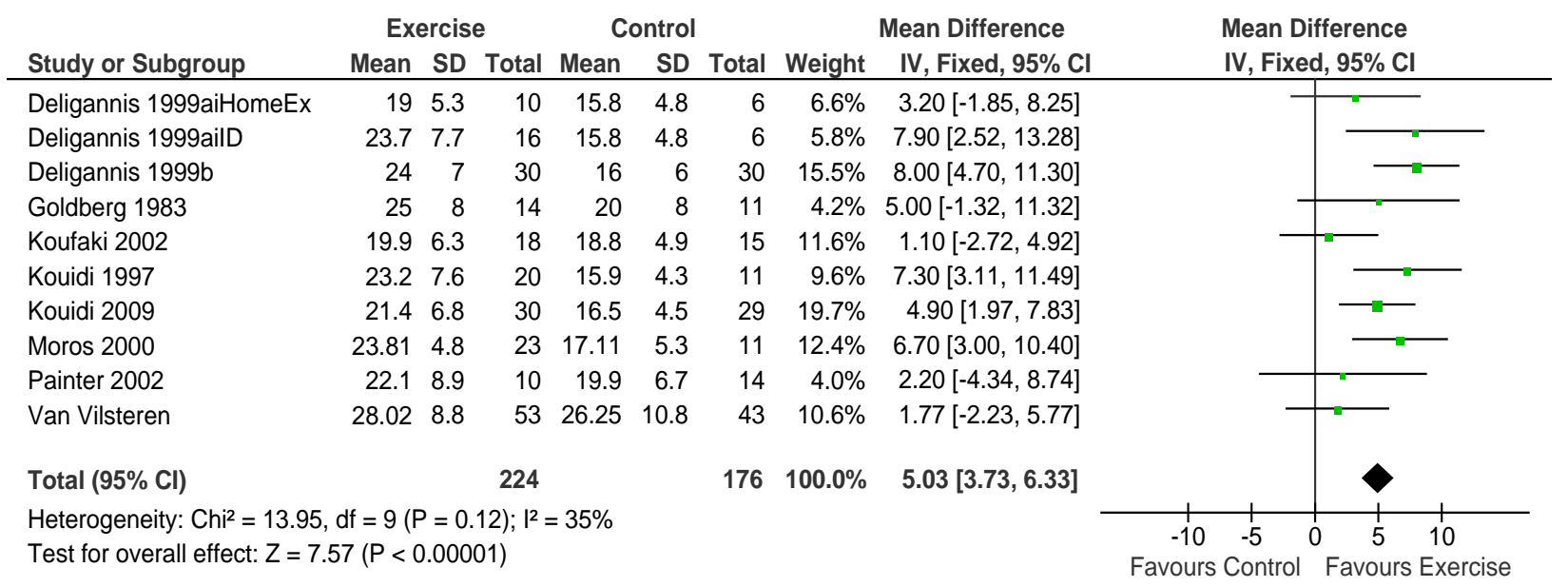

Figure 1. Comparison of peak $\mathrm{VO}_{2}\left(\mathrm{mlO}_{2} \cdot \mathrm{kg}^{-1} \cdot \mathrm{min}^{-1}\right)$ following exercise training in $\mathrm{HD}$ patients.

Table 1. Summary characteristics of included studies.

\begin{tabular}{|c|c|c|c|c|}
\hline Haemodialysis studies & $\mathbf{N}(\operatorname{ExT})$ & Training & Study duration, delivery method & Data extracted \\
\hline Afshar, $2010[30]$ & $21(7 \mathrm{AT}, 7 \mathrm{RT})$ & $\mathrm{AT}, \mathrm{RT}$ & 2 months, ID & $\mathrm{Cr}, \mathrm{Kt} / \mathrm{V}, \mathrm{Hb}$, Albumin, CRP, Chol \\
\hline Chen, 2010 [24] & $50(25)$ & RT & 4 Months ID & Strength \\
\hline Daniilidis 2004 [31] & $34(20)$ & $\mathrm{AT}$ & 3 Months, ID & IL-6 \\
\hline Deligiannis, 1999 [14] & $16(10)$ & $\mathrm{CT}$ & 6 months, ND, outpatient & Peak $\mathrm{VO}_{2}$, Biochemistry, BP, LVMI, LVEF \\
\hline Deligiannis, 1999 [14] & $22(16)$ & $\mathrm{CT}$ & 6 months, ND, home & Peak $\mathrm{VO}_{2}$, Biochemistry, BP, LVMI, LVEF \\
\hline Deligiannis, 1999 [7] & $60(30)$ & $\mathrm{CT}$ & 6 months, ND & Peak $\mathrm{VO}_{2}, \mathrm{HRV}$, Biochemistry \\
\hline De Paul, 2002 [22] & $38(18)$ & $\mathrm{CT}$ & 5 months, ND & 6MWD, BP, Biochemistry \\
\hline Dong, 2011 [27] & $32(15)$ & $\mathrm{RT}$ & 6 months ID & BMI, Biochemistry, Kcals \\
\hline Frey, 1999 [28] & $11(5)$ & AT & 2 months, ID & Kcals, Kt/V, Albumin \\
\hline Goldberg, 1983 [19] & $25(14)$ & AT & 12 months, ND & Peak $\mathrm{VO}_{2}$ \\
\hline Johansen, 2006 [33] & $79(40)$ & $\mathrm{RT}$ & 3 months, ID & Muscle strength, $\mathrm{Cr}$ \\
\hline Koh, $2010[21]$ & $70(43)$ & AT & 6 months, cycling, ID & SF-36, 6MWD, BP \\
\hline Koufaki, 2002 [15] & $18(15)$ & AT & 3 months, cycling, ID & Peak $\mathrm{VO}_{2}$, Kcals, $\mathrm{Hb}$, Albumin, BMI \\
\hline Kouidi, 1997 [4] & $31(20)$ & AT & 6 months, ND & Peak $\mathrm{VO}_{2}, \mathrm{BDI}$ \\
\hline Kouidi, 2009 [6] & $59(30)$ & $\mathrm{CT}$ & 10 months, cycling ID & Peak $\mathrm{VO}_{2}$, LVMI, LVEF, HRV, Hb \\
\hline Kouidi, 2010 [5] & $44(24)$ & $\mathrm{CT}$ & 12 months, ID & BDI (other data already used Kouidi 2009) \\
\hline Makhlough, 2012 [32] & $48(25)$ & AT & 2 months ID & Biochemistry \\
\hline Moros-Garcia, 2000 [16] & $34(23)$ & $\mathrm{AT}$ & 4 months, cycling ND & Peak $\mathrm{VO}_{2}$ \\
\hline Oliveros, 2011 [23] & $15(9)$ & $\mathrm{CT}$ & 4 months ND & Strength, SF-36, BDI, 6MWD, Kt/V \\
\hline Painter, 2002 [17] & $24(10)$ & AT & 5 months, cycling, ID & Peak $\mathrm{VO}_{2}, \mathrm{SF}-36$ \\
\hline Parsons, 2004 [37] & $13(6)$ & AT & 2 months cycling, ID & SF-36 \\
\hline Reboredo, 2010 [29] & $22(11)$ & $\mathrm{AT}$ & 3 months, ID & HRV, LVEF, KT/V, Biochemistry, LVMI \\
\hline Van Vilsteren, 2005 [18] & $96(53)$ & $\mathrm{CT}$ & 3 months, cycling ID & Peak $\mathrm{VO}_{2}, \mathrm{SF}-36, \mathrm{LVMI}$ \\
\hline Willund, 2010 [26] & $17(8)$ & $\mathrm{AT}$ & 4 months, ID cycling & BMI, IL-6, CRP, biochemistry, BP, LVMI \\
\hline
\end{tabular}

ExT: exercise training; RT: resistance training; AT: aerobic training; CT: combined training; ND: exercise on non-dialysis days; ID: exercise on dialysis days; HRV: heart rate variability; LVEF\%: left ventricular ejection fraction; SF-36: short form 36 health questionnaire; BDI: beck depression inventory; Cr: serum creatinine; Hb: haemoglobin; Kt/V: dialysis adequacy index; CRP: C-reactive protein; Chol: total serum cholesterol; LVMI: left ventricular mass index; Kcals: daily energy intake (kilocalories); BP: blood pressure; 6MWD: six minute walk distance. 
Table 2. Assessment of study quality-JADAD score.

\begin{tabular}{|c|c|c|c|c|}
\hline Haemodialysis studies & Randomized & Blinding & Withdrawn & Jadad score \\
\hline Ashfar, 2010 [30] & Yes & Unclear & Unclear & 1 \\
\hline Chen, 2010 [24] & Yes & Yes & Yes & 3 \\
\hline Daniilidis, 2004 [31] & Yes & Unclear & Yes & 2 \\
\hline Deligiannis, 1999 [14] & Yes & Unclear & No & 1 \\
\hline Deligiannis, 1999 [7] & Yes & Unclear & Unclear & 1 \\
\hline De Paul, 2002 [22] & Yes & Yes & Yes & 3 \\
\hline Dong, 2011 [27] & Yes & Unclear & Yes & 2 \\
\hline Frey, 1999 [28] & Yes & Unclear & Yes & 2 \\
\hline Goldberg ,1983 [19] & Yes & Unclear & Yes & 2 \\
\hline Johansen, 2006 [33] & Yes & Yes & Yes & 3 \\
\hline Koh, 2010 [21] & Yes & No & Yes & 2 \\
\hline Koufaki, 2002 [15] & Yes & Unclear & Yes & 2 \\
\hline Kouidi, 1997 [4] & Yes & Unclear & Yes & 2 \\
\hline Kouidi, 2009 [6] & Yes & Yes & Yes & 3 \\
\hline Kouidi, 2010 [5] & Yes & Yes & Yes & 3 \\
\hline Makhlough, 2012 [32] & Yes & Yes & Yes & 3 \\
\hline Moros-Garcia, 2000 [16] & Yes & Unclear & Yes & 2 \\
\hline Oliveros, 2011 [23] & Yes & Unclear & Yes & 2 \\
\hline Painter, 2002 [17] & Yes & Unclear & Yes & 2 \\
\hline Parsons, 2004 [37] & Yes & Unclear & Yes & 2 \\
\hline Reboredo, 2010 [29] & Yes & Yes & Yes & 3 \\
\hline Van Vilsteren, 2005 [18] & Yes & Unclear & Yes & 2 \\
\hline Willund, 2010 [26] & Yes & Yes & Yes & 3 \\
\hline
\end{tabular}

study duration on change in peak $\mathrm{VO}_{2}$ in 9 studies. First, we removed the four studies that employed an exercise training program of less than 6 months from the analysis [15-18], mean change in peak $\mathrm{VO}_{2}$ for the five studies of 6 months for longer was $32.1 \% \pm 8.9 \%$, while the four shorter duration studies yielded a significantly lower peak $\mathrm{VO}_{2}$ change of $16.2 \% \pm 5.3 \%(\mathrm{p}=0.002)$.

\subsection{Effect of Exercise Modality and Delivery}

Four studies of combined aerobic (AT) and strength (ST) training $[6,7,14,18]$ appear to convey a weighted mean $28.6 \% \pm 11.4 \%$ improvement in peak $\mathrm{VO}_{2}$ compared to five isolated AT studies $[4,15,16,17,19]$ which produced a weighted mean $22.2 \% \pm 9.7 \%$ improvement in peak $\mathrm{VO}_{2}(\mathrm{p}=0.37)$. None of the isolated resistance studies reported peak $\mathrm{VO}_{2}$. Four studies $[6,15,17,18]$ used interdialytic training (ID) and also reported weighted mean change in peak $\mathrm{VO}_{2}$ was $17.8 \% \pm 7.7 \%$ while the five studies $[4,7,14,16,19]$ using exercise training on nondialysis days showed $30.8 \% \pm 9.6 \%$ improvement in peak $\mathrm{VO}_{2}(\mathrm{p}=0.07)$. One study[20] directly compared exercise training induced improvements in peak $\mathrm{VO}_{2}$ at 12 months with outpatient (ND) and (ID) training programs $38 \%$ versus $31 \%$ respectively $(p=0.07)$. Only two studies [14,21] examined home versus outpatient exercise with conflicting results. The former study [21] showed a greater improvement in six minute walk distance in the home group, while the latter study [20] reported a larger peak $\mathrm{VO}_{2}$ improvement in the out-patient versus home exercise patients.

\subsection{Walking Distance}

Data from three studies [21-23] in 80 haemodialysis patients showed an improvement in six-minute walking 
Table 3. Excluded randomized controlled trials.

\begin{tabular}{|c|c|}
\hline Akiba $1995[38]$ & No relevant outcome data \\
\hline Balakrishnan, 2009 [39] & No relevant outcome data \\
\hline Carney, 1987 [40] & No relevant outcome data \\
\hline Castenada, $2001[41]$ & Non-HD patients \\
\hline Castenada, $2004[42]$ & Non-HD patients \\
\hline Chang, 2010 [43] & Relevant outcome data reported by physical activty levels \\
\hline Cheema, 2007 [44] & Data could not be converted to post mean/standard deviation \\
\hline Cheema, 2007 [45] & Data could not be converted to post mean/standard deviation \\
\hline Cheema, 2011 [46] & Data could not be converted to post mean/standard deviation \\
\hline Chen, 2010 [47] & Non-HD patients \\
\hline Fitts, 1999 [48] & No relevant outcome data \\
\hline Flesher, 2011 [49] & No relevant outcome data. Intervention included cooking classes \\
\hline Goldberg, 1986 [50] & Duplicate Goldberg, 1983; Harter, 1985 \\
\hline Harter, 1985 [51] & Duplicate Goldberg, 1983; Goldberg, 1986 \\
\hline Headley, 2008 [52] & Acute exercise response, not training study \\
\hline Konstantinou, 2002 [53] & Duplicate, control group data shared with Deligannis, 1999 \\
\hline Kouidi, 2004 [20] & No sedentary control group \\
\hline Leehey, 2009 [54] & Non-HD patients \\
\hline Matsumoto, 2007 [55] & Only baseline data reported \\
\hline Molstead, 2004 [56] & Data reported as median and range \\
\hline Mustata, 2011 [57] & Non-HD patients \\
\hline Ouzouni, 2009 [58] & Possible duplicate with Kouidi, 2009 and Kouidi, 2010 \\
\hline Painter, 2002 [59] & Included transplant patients not receiving hemodialysis \\
\hline Petraki, 2008 [35] & Possible duplicate with Kouidi, 2009 \\
\hline Segura-Orti, 2009 [60] & Possible duplicate with Kouidi, 2009 \\
\hline
\end{tabular}

distance MD 60.7 metres (95\% CI 18.9, 102.5 metres, $\mathrm{p}$ $=0.004$ ) see Figure 2 .

\subsection{Muscle Strength}

Three studies [23-25] reported knee extensor muscle strength in 95 HD patients, improvements were seen in exercising patients versus sedentary controls, MD 2.99 $\mathrm{kg}(95 \%$ CI $0.46,5.52, \mathrm{p}=0.02)$, see Figure 3.

\subsection{Erythropoietin (EPO) Use}

As EPO use may have had significant impact on exercise training adaptations, particularly peak $\mathrm{VO}_{2}$, relevant sub-analyses may have been informative, but this was not justified as thirteen of the HD studies did not provide details of patient EPO use during the studies. Three stud- ies did however keep EPO use stable and the remaining eight studies targeted EPO use to haemoglobin levels, but only four of these 11 studies reported peak $\mathrm{VO}_{2}$ rendering sub-analyses impractical.

\subsection{Body Mass Index, Energy Intake, Serum Albumin and Inflammation}

Three studies [15,26,27] reported post-training body mass index in $72 \mathrm{HD}$ patients, BMI was not different between exercise and control participants MD 1.15 $\mathrm{kg} \cdot \mathrm{m}^{-2}(95 \% \mathrm{CI}-0.33,2.63, \mathrm{p}=0.13)$, see Figure 4. Three studies $[15,27,28]$ including 66 patients, employed dietary recall to estimate daily energy intake, exercise participants increased their intake by $4 \%$ from baseline. Meta-analysis, showed daily energy intake to be significantly higher in those who exercised versus controls MD 


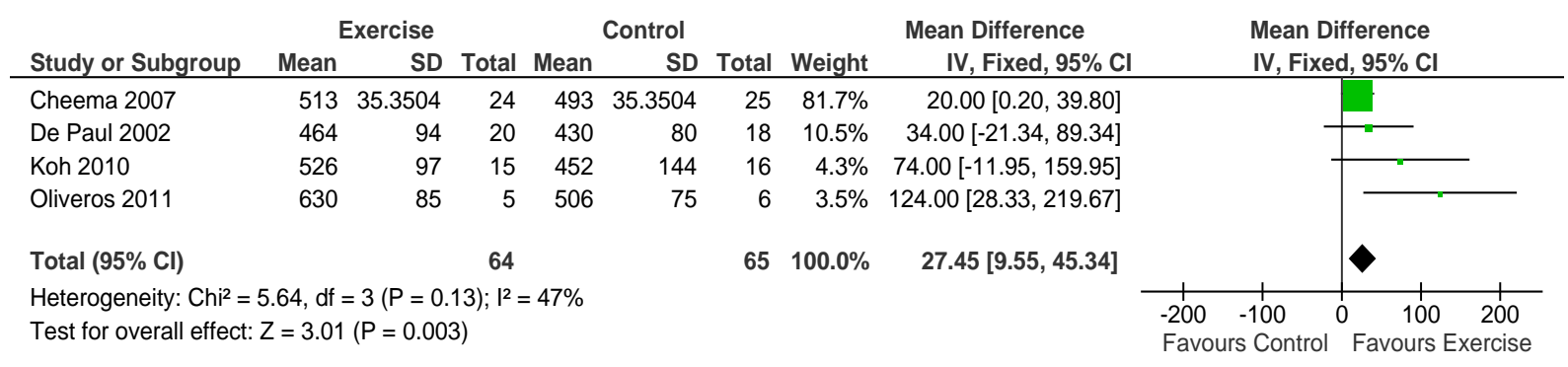

Figure 2. Comparison of six-minute walk distance (Metres) following exercise training in HD patients.

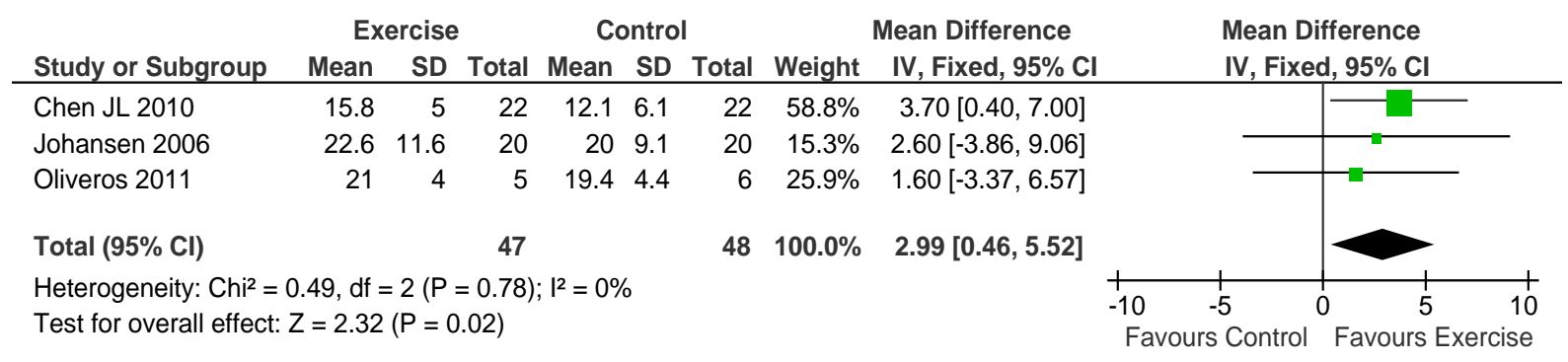

Figure 3. Comparison of knee-extensor strength (kg) following exercise training in HD patients.

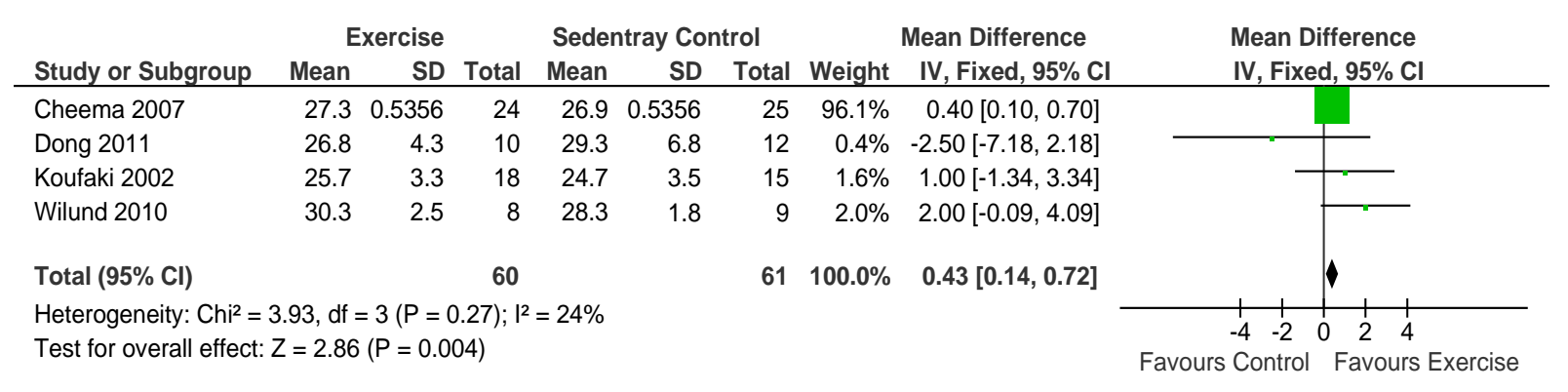

Figure 4. Comparison of BMI $\left(\mathrm{kg} \cdot \mathrm{m}^{-2}\right)$ following exercise training in HD patients.

$238 \mathrm{Kcal}^{-\mathrm{day}^{-1}}(95 \%$ CI 94, 383, $\mathrm{p}=0.001)$, see Figure 5. Figure 6 shows a forest plot of 6 studies [15,26-30] reporting serum albumin in 126 HD patients. Albumin was significantly lower in exercising versus sedentary controls $\mathrm{MD}-0.07 \mathrm{~g} \cdot \mathrm{L}^{-1}(95 \% \mathrm{CI}-0.16,-0.01, \mathrm{p}=$ $0.08)$. Two studies $[26,31]$ reported post-training serum levels of interleukin-6 (pg/ml) in 49 patients, IL-6 was significantly lower in exercising HD patients versus sedentary controls MD- $0.58 \mathrm{pg} \cdot \mathrm{ml}^{-1}(95 \% \mathrm{CI}-1.01,-0.15$, $\mathrm{p}=0.008$ ), see Figure 7. Two studies [26,30] reported post-training serum levels of C-reactive protein in 38 patients, CRP was significantly higher in exercising HD patients versus sedentary controls MD $0.92 \mathrm{mg} / \mathrm{L}^{-1}(95 \%$ CI $0.29,1.56, \mathrm{p}=0.004$ ), see Figure 8 .

\subsection{Cardiac Function}

Following analysis of three studies $[6,14,29]$ in 119 patients, a non-significant trend towards improved left ventricular ejection fraction was observed post-intervention in exercise training patients MD 2.8\% (95\% CI -1.4 ,
$6.9 \%, \mathrm{p}=0.20)$

\subsection{Depression and Self-Reported Health (SF-36)}

Three studies $[4,5,23]$ reported Beck depression score (BDI) in $86 \mathrm{HD}$ patients, BDI score was significantly lower (improved) in exercising patients versus sedentary controls MD -6.9 (95\% CI -9.7, -4.1, p < 0.00001), see Figure 9. Neither the physical or mental components of SF-36 general health questionnaire were improved following exercise training.

\subsection{Dialysis Related Biochemistry}

Figure 10 shows four studies [23,28-30] reported dialysis adequacy index in 54 patients, $\mathrm{Kt} / \mathrm{V}$ was significantly lower in exercising patients versus sedentary controls MD -0.25 (95\% CI $-0.34,-0.17, \mathrm{p}<0.00001)$. Figure 11 shows 6 studies $[4,6,7,14,26,32]$ reporting serum potassium in 253 patients, potassium was higher in exercising 


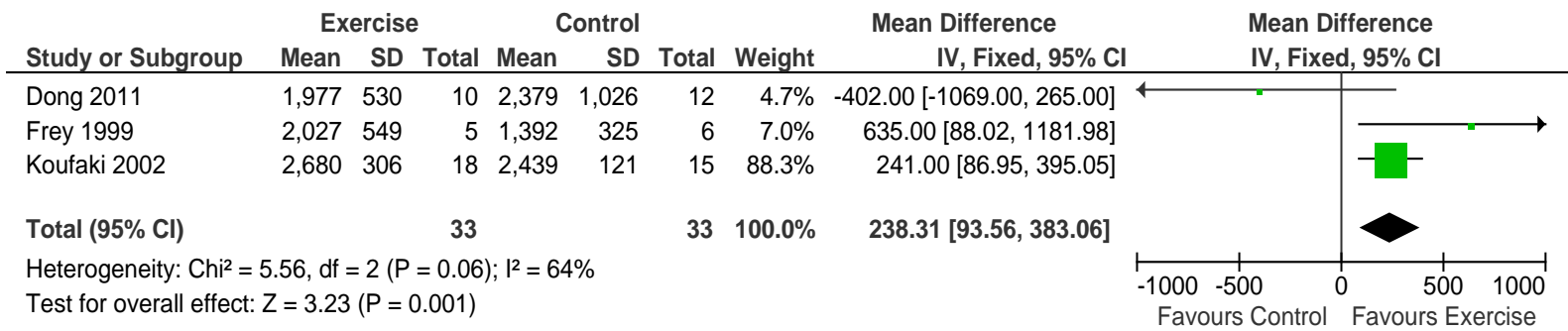

Figure 5. Comparison of daily energy intake $\left(\mathrm{Kcals}^{\prime} \mathrm{day}^{-1}\right)$ following exercise training in HD patients.

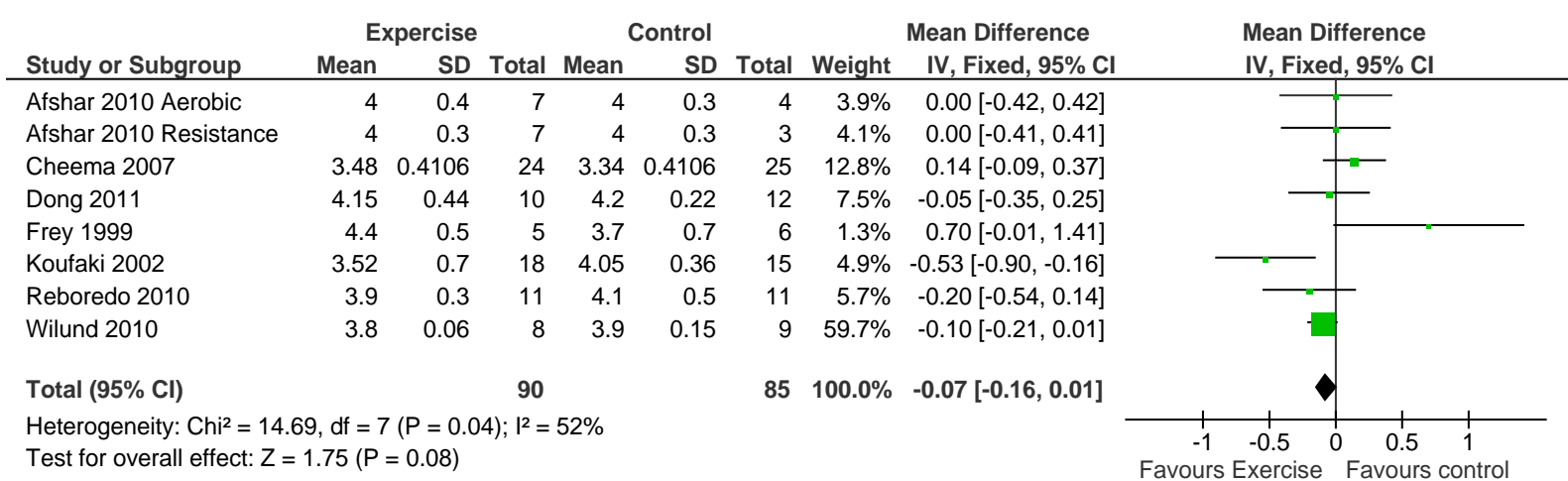

Figure 6. Comparison of serum albumin $\left(g \cdot \mathrm{L}^{-1}\right)$ following exercise training in HD patients.

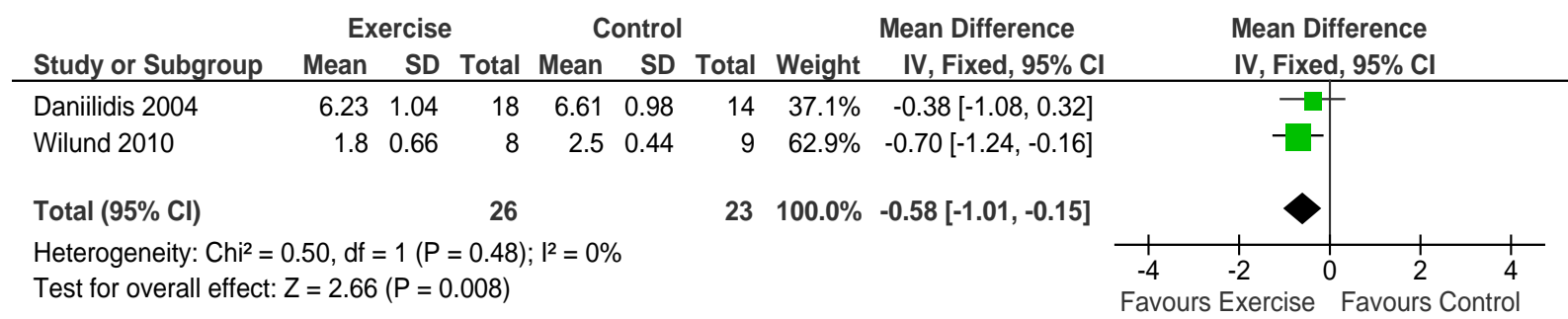

Figure 7. Comparison of serum interleukin-6 $\left(\mathrm{pg} \cdot \mathrm{ml}^{-1}\right)$ following exercise training in HD patients.

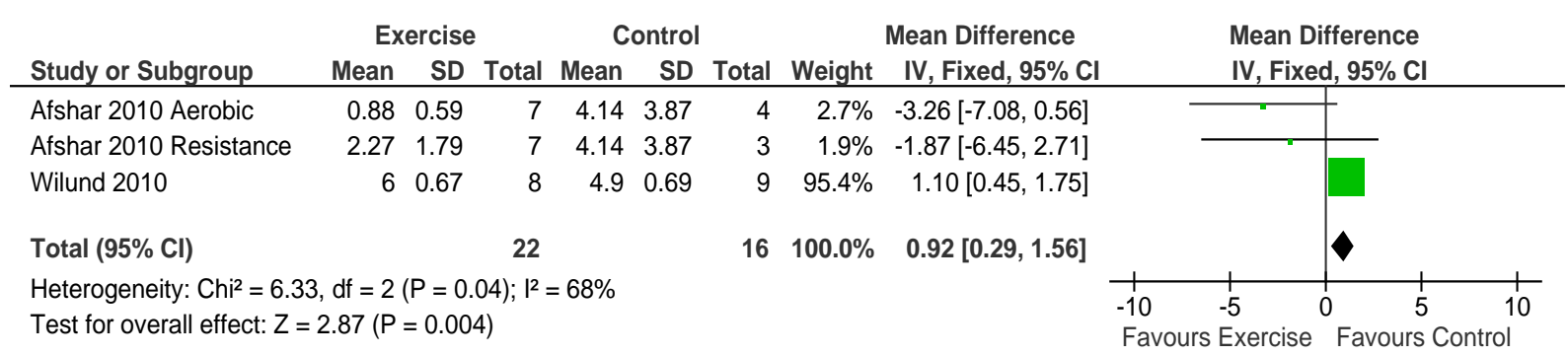

Figure 8. Comparison of C-reactive protein $\left(\mathrm{mg} \cdot \mathrm{L}^{-1}\right)$ following exercise training in HD patients.

patients versus sedentary controls $\mathrm{MD} 0.14 \mathrm{mmol} \cdot \mathrm{L}^{-1}$ (95\% CI 0.01, 0.27, $\mathrm{p}=0.04)$.

\subsection{Exercise Eligibility, Adherence and Safety}

The following studies provided a complete CONSORT $[6,18,21,22,24,27,29,33]$ statement. Two other studies [4, 15] provided partial data about eligibility, withdrawal and completion. Data from these studies showed that of 1421 patients approached for suitability for exercise training 551 or nearly $39 \%$ were ineligible due to various medical exclusion criteria. Exercise training appears safe with no deaths reported during exercise training in over 30,000 patients-hours of exercise.

\subsection{Study Quality and Effect of Publication Bias}

JADAD score [11] was used to assess study quality. We used a modified JADAD score on a scale $0-3$, based 


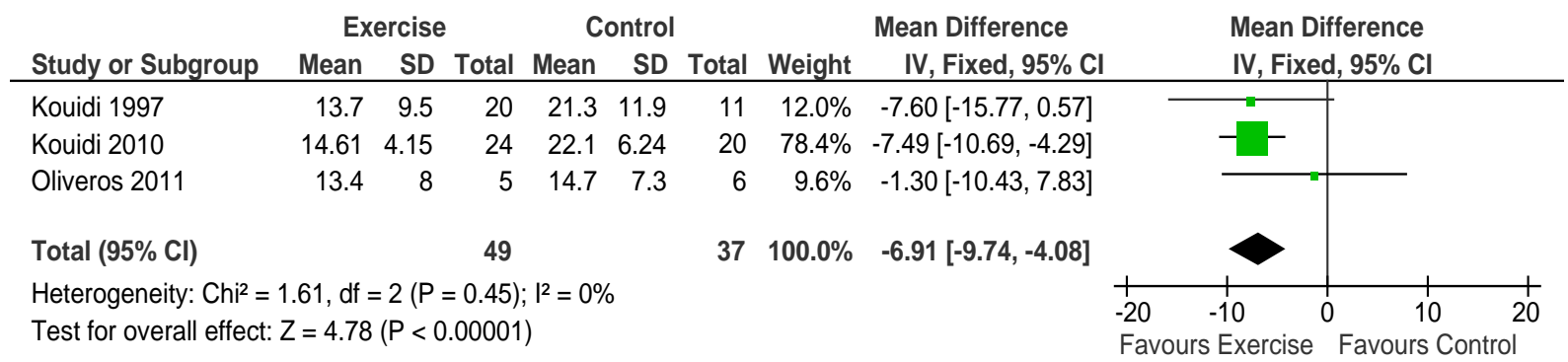

Figure 9. Comparison of Beck depression inventory following exercise training in HD patients.

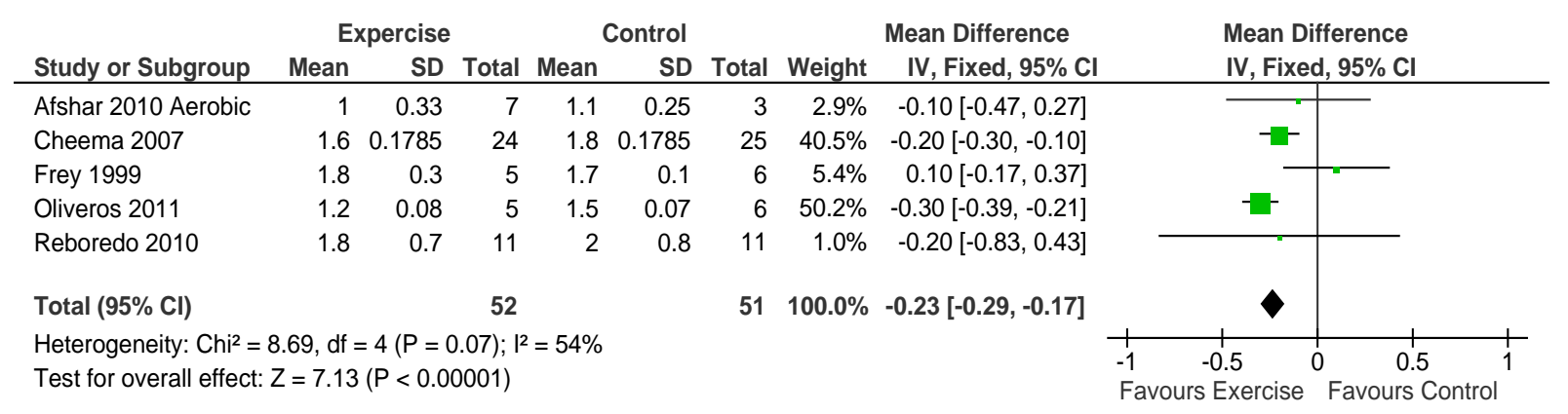

Figure 10. Comparison of dialysis adequacy index following exercise training in HD patients.

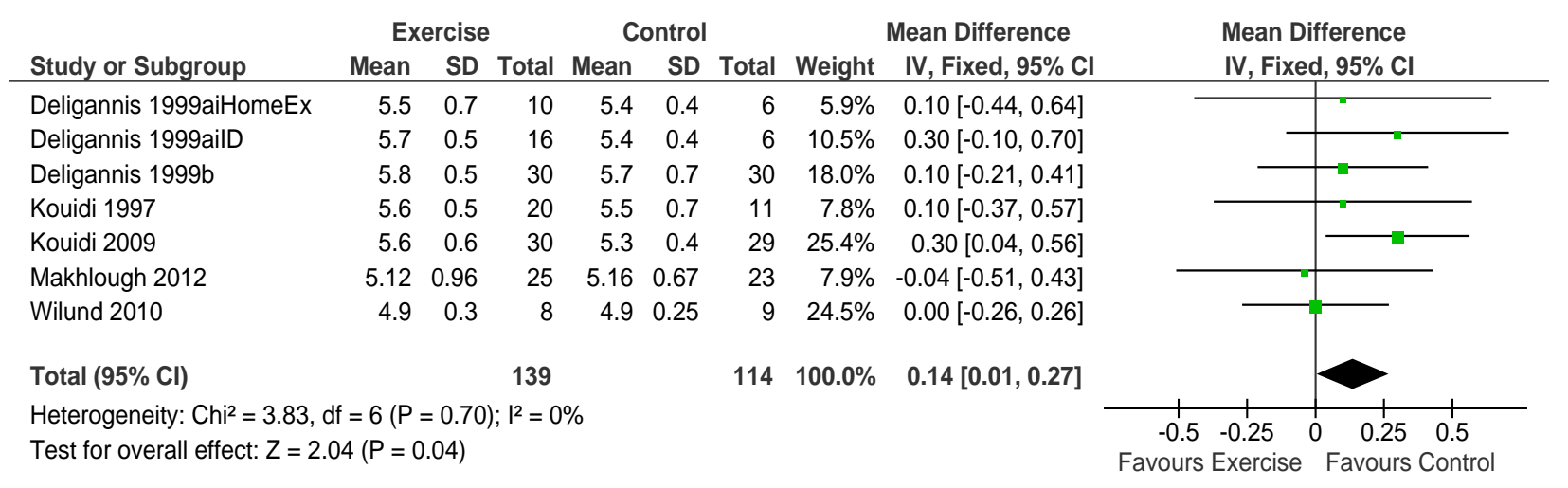

Figure 11. Comparison of serum potassium $\left(\mathrm{mmol} \cdot \mathrm{L}^{-1}\right)$ following exercise training in $\mathrm{HD}$ patients.

upon investigator blinding, randomization of participants and reporting of participant withdrawals. Median JADAD was 2, three studies scored 1, 12 studies scored 2 and 13 studies scored 3. Funnel plots showed little evidence of publication bias.

\subsection{Study Heterogeneity}

Studies were extremely well matched for age, gender and baseline peak $\mathrm{VO}_{2}$. Cochran Q tests revealed low $(<50 \%)$ $\mathrm{I}^{2}$ values for all but 3 analyses suggesting little heterogeneity between studies, these values indicate it was appropriate to pool data for all analyses except CRP, energy intake and dialysis adequacy.

\section{Discussion}

Our review includes previously unreported pooled analy- ses of changes in energy balance, dialysis adequacy, serum potassium, patient adherence recruitment and safety post-exercise training. Our work also provides a clinical update on pooled analyses undertaken following exercise training in studies of CKD patients published to date. Our work suggests that exercise training for patients undertaking HD is safe.

The mean baseline peak $\mathrm{VO}_{2}$ value for $\mathrm{HD}$ patients is approximately $20 \mathrm{mlO}_{2} \cdot \mathrm{kg}^{-1} \cdot \mathrm{min}^{-1}$, previous work has demonstrated that a peak $\mathrm{VO}_{2}$ of $17.5 \mathrm{mlO} \cdot \mathrm{kg}^{-1} \cdot \mathrm{min}^{-1}$ or less is associated with poor survival [8], so exercise training is likely to assist most those at risk of falling below this threshold. Data extracted demonstrates included patients showed reduced baseline peak $\mathrm{VO}_{2}$ approximately $30 \%$ below age-adjusted norms. We observed that exercise training produces varied improvements in peak $\mathrm{VO}_{2}$ depending on the type, increasing 
duration and intra-dialytic delivery of exercise. Our data suggest either combined aerobic and resistance exercise or isolated aerobic exercise, delivered on non-dialysis days, for at least 6 months is likely to offer the greatest magnitude of change in peak $\mathrm{VO}_{2}$. Data on isolated resistance exercise in HD patients is limited currently. The magnitude of change in peak $\mathrm{VO}_{2}$ in programs of $2-6$ months duration concur with the $17 \%$ previously reported in HD patients [17,33], although only about a $12 \%$ improvement can be expected at 3 months. Larger increments $(>30 \%)$ in post-training peak $\mathrm{VO}_{2}$ have been observed in patients who complete combined aerobic and strength training for 6 months or more on non-dialysis days $[7,14]$. Moreover exercise training restores much of the deficit in age-adjusted peak $\mathrm{VO}_{2}$ and meta-regression showed the extent of peak $\mathrm{VO}_{2}$ restoration is positively correlated with increasing exercise training duration.

Our 6-minute walk data confirmed that the improvements in peak $\mathrm{VO}_{2}$ were associated with improved physical function. One must remember though that such large improvements in peak $\mathrm{VO}_{2}$ are facilitated because patients are often concurrently given erythropoietin (EPO) and optimizing oxygen carrying capacity of the blood will increase the potential to adapt to exercise training. The included studies had great variation in the criteria for managing EPO use.

Outcomes pertaining to muscle size and strength were available from three studies, these data suggest muscle size and strength can be improved via resistance training. The optimal exercise training program is therefore likely to retard muscle-wasting and improve muscle cross sectional area and strength, although there is an obvious need for a large, well-designed, randomized, controlled trial of resistance training in HD patients.

Three studies [15,27,28] reported exercising patients reported raised daily energy intakes by $238 \mathrm{Kcal} \cdot \mathrm{day}^{-1}$ or $1666 \mathrm{Kcal} \cdot$ week $^{-1}$. We estimate that exercise training energy expenditures from these studies are of the order of $1000 \mathrm{Kcal}$ per week, providing a weekly energy surplus of about $670 \mathrm{Kcal}$. Despite this the four studies measuring change in BMI did not report a significant net gain. Data from heart failure studies suggest weight gain, especially body fat is beneficial [34], but this finding has yet to be established for HD patients even though intuittively poor nutrition is associated with muscle wasting, de-conditioning and the catabolic state. Serum levels of both interleukin-6 and C-reactive protein were both favourably attenuated following exercise training, suggesting that muscle mass can be preserved in HD patients and end stage cachexia delayed in those at risk.

Beck Depression score was impaired at baseline but did improve significantly. Baseline Beck depression data from this meta-analysis suggest values consistent with moderate to severe depression, which was significantly reduced post-training, in those who exercised [5], so exercise training may have benefit beyond the partial restoration of peak $\mathrm{VO}_{2}$ deficits.

Dialysis Adequacy $(\mathrm{kt} / \mathrm{v})$ was lower in exercising versus control patients. Lower $\mathrm{kt} / \mathrm{v}$ indicates that a smaller amount of fluid needs to be removed during dialysis and therefore there may be less strain on the cardiovascular system. Serum potassium was also higher in exercising patients which is likely to reduce fluid retention and this may be linked to changes observed in $\mathrm{kt} / \mathrm{v}$. The risk of hypotensive episodes during intra-dialytic exercise, due to fluid removal during dialysis, may preclude patients from achieving similar durations and activities of exercise that could be accomplished on non-dialysis days [35], however our analyses of this review suggest that adaptation to exercise may attenuate the risks associated with fluid removal.

To date no randomized, controlled, study of exercise training in patients with chronic renal failure has reported a death directly related to exercise in over 30,000 patient-hours of exercise. An analysis of exercise training study withdrawal suggests exercise patients are no more likely than control patients to drop out of a study. One may therefore postulate that exercise training for HD patients is safe and the derived benefits outweigh the risk of adverse events such as hypotensive or ischemic episodes.

Kidney Disease International recently recommended exercise training for people with chronic renal disease to guide specialist and allied health teams to incorporate exercise training into their clinical services [36]. Perhaps of most interest would be a long-term randomized, controlled trial of exercise training that examines the primary outcome measures of mortality, including cardiovascular mortality, hospitalization and cost-effectiveness in dialysis or preferably, pre-dialysis patients.

The limitations of this work were varying exercise program parameters; durations, type of delivery (intraversus inter-dialytic), modalities (aerobic or resistance or combined), intensity. Moreover a wide range of outcome measures were employed, studies were generally small and strict eligibility criteria mean healthier patients were more likely to be selected. Despite these limitations included studies are exceptionally well matched in terms of age, gender and peak $\mathrm{VO}_{2}$ at baseline for exercise and control group participants. Publication bias may affect the results although funnel plotting peak $\mathrm{VO}_{2}$ changes suggest bias was minimal.

\section{Conclusion}

Our pooled analyses produced novel findings that exercise training may improve dialysis efficiency $(\mathrm{kt} / \mathrm{v})$, serum potassium, inflammation and depression in HD pa- 
tients. Our analyses also confirm improvements in peak $\mathrm{VO}_{2}$, muscle strength, walking distance and energy intake.

\section{REFERENCES}

[1] B. S. Cheema and M. A. Singh, "Exercise Training in Patients Receiving Maintenance Hemodialysis: A Systematic Review of Clinical Trials," American Journal of Nephrology, Vol. 25, No. 4, 2005, pp. 352-364. doi:10.1159/000087184

[2] E. J. Howden, R. G. Fassett, N. M. Isbel and J. S. Coombes, "Exercise Training in Chronic Kidney Disease Patients," Sports Medicine, Vol. 42, No. 6, 2012, pp. 473488. doi:10.2165/11630800-000000000-00000

[3] K. L. Johansen and P. Painter, "Exercise in Individuals with CKD," American Journal of Kidney Diseases, Vol. 59, No. 1, 2012, pp. 126-134. doi:10.1053/j.ajkd.2011.10.008

[4] E. Kouidi, A. Iacovides, P. Iordanidis, S. Vassiliou, A. Deligiannis, C. Ierodiakonou and A. Tourkantonis, "Exercise Renal Rehabilitation Program: Psychosocial Effects," Nephron Clinical Practice, Vol. 77, No. 2, 1997, pp. 152-158.

[5] E. Kouidi, V. Karagiannis, D. Grekas, A. Iakovides, G. Kaprinis, A. Tourkantonis and A. Deligiannis, "Depression, Heart Rate Variability, and Exercise Training in Dialysis Patients," European Journal Cardiovascular Prevention Rehabilitation, Vol. 17, No. 2, 2010, pp. 160-167. doi:10.1097/HJR.0b013e32833188c4

[6] E. J. Kouidi, D. M. Grekas and A. P. Deligiannis, "Effects of Exercise Training on Noninvasive Cardiac Measures in Patients Undergoing Long-Term Hemodialysis: A Randomized Controlled Trial," American Journal of Kidney Diseases, Vol. 54, No. 3, 2009, pp. 511-521. doi:10.1053/j.ajkd.2009.03.009

[7] A. Deligiannis, E. Kouidi and A. Tourkantonis, "Effects of Physical Training on Heart Rate Variability in Patients on Hemodialysis," American Journal of Cardiology, Vol. 84, No. 2, 1999, pp. 197-202. doi:10.1016/S0002-9149(99)00234-9

[8] K. E. Sietsema, A. Amato, S. G. Adler and E. P. Brass, "Exercise Capacity as a Predictor of Survival among Ambulatory Patients with End-Stage Renal Disease," Kidney International, Vol. 65, No. 2, 2004, pp. 719-724. doi:10.1111/j.1523-1755.2004.00411.x

[9] N. Smart and M. Steele, "Exercise Training in Haemodialysis Patients: A Systematic Review and Meta-Analysis," Nephrology (Carlton), Vol. 16, No. 7, 2011, pp. 626632.

[10] E. Segura-Orti, "Exercise in Haemodyalisis Patients: A Literature Systematic Review," Nefrologia, Vol. 30, No. 2, 2010, pp. 236-246.

[11] A. R. Jadad, R. A. Moore, D. Carroll, C. Jenkinson, D. J. Reynolds, D. J. Gavaghan and H. J. McQuay, "Assessing the Quality of Reports of Randomized Clinical Trials: Is Blinding Necessary?" Controlled Clinical Trials, Vol. 17, No. 1, 1996, pp. 1-12.

\section{doi:10.1016/0197-2456(95)00134-4}

[12] P. Alderson and S. Green, "Cochrane Collaboration Open Learning Material for Reviewers," Version 1.1, 2002. http://www.cochrane-net.org/openlearning/PDF/Openlear ning-full.pdf

[13] J. P. T. Higgins, S. G. Thompson, J. J. Deeks and D. G. Altman, "Measuring Inconsistency in Meta-Analysis," British Medical Journal, Vol. 327, No. 7414, 2003, pp. 557-560. doi:10.1136/bmj.327.7414.557

[14] A. Deligiannis, E. Kouidi, E. Tassoulas, P. Gigis, A. Tourkantonis and A. Coats, "Cardiac Effects of Exercise Rehabilitation in Hemodialysis Patients," International Journal of Cardiology, Vol. 70, No. 3, 1999, pp. 253-266. doi:10.1016/S0167-5273(99)00090-X

[15] P. Koufaki, T. H. Mercer and P. F. Naish, "Effects of Exercise Training on Aerobic and Functional Capacity of End-Stage Renal Disease Patients," Clinical Physiology and Functional Imaging, Vol. 22, No. 2, 2002, pp. 115124. doi:10.1046/i.1365-2281.2002.00405.x

[16] G. Moros, R. Ros Mar, A. A. Villarroya, A. C. L. de Robles, M. Comin and S. Nerin Ballarriga, "Physical Exercise in Hemodialysis Patients," Archivos de Medicina del Deporte, Vol. 17, No. 77, 2000, pp. 235-244.

[17] P. Painter, G. Moore, L. Carlson, S. Paul, J. Myll, W. Phillips and W. Haskell, "Effects of Exercise Training plus Normalization of Hematocrit on Exercise Capacity and Health-Related Quality of Life," American Journal of Kidney Diseases, Vol. 39, No. 2, 2002, pp. 257-265. doi:10.1053/ajkd.2002.30544

[18] M. C. Van Vilsteren, M. H. de Greef and R. M. Huisman, "The Effects of a Low-to-Moderate Intensity Pre-Conditioning Exercise Programme Linked with Exercise Counselling for Sedentary Haemodialysis Patients in The Netherlands: Results of a Randomized Clinical Trial," $\mathrm{Ne}$ phrology Dialysis Transplantation, Vol. 20, No. 1, 2005, pp. 141-146. doi:10.1093/ndt/gfh560

[19] A. P. Goldberg, E. M. Geltman, J. M. Hagberg, J. R. Gavin III, J. A. Delmez, R. M. Carney, A. Naumowicz, M. H. Oldfield and H. R. Harter, "Therapeutic Benefits of Exercise Training for Hemodialysis Patients," Kidney International Supplements, Vol. 16, 1983, pp. S303-S309.

[20] E. Kouidi, D. Grekas, A. Deligiannis and A. Tourkantonis, "Outcomes of Long-Term Exercise Training in Dialysis Patients: Comparison of Two Training Programs," Clinical Nephrology, Vol. 61, Suppl. 1, 2004, pp. S31-S38.

[21] K. P. Koh, R. G. Fassett, J. E. Sharman, J. S. Coombes and A. D. Williams, "Intradialytic versus Home-Based Exercise Training in Hemodialysis Patients: A Randomised Controlled Trial," BMC Nephrology, Vol. 10, 2009, p. 2.

[22] V. DePaul, J. Moreland, T. Eager and C. M. Clase, "The Effectiveness of Aerobic and Muscle Strength Training in Patients Receiving Hemodialysis and EPO: A Randomized Controlled Trial," American Journal Kidney Diseases, Vol. 40, No. 6, 2002, pp. 1219-1229. doi:10.1053/ajkd.2002.36887

[23] R. M. Oliveros, M. Avendano, D. Bunout, S. Hirsch, M. P. De La Maza, C. Pedreros and H. Muller, "A Pilot Study on Physical Training of Patients in Hemodialysis," 
Revista Médica de Chile, Vol. 139, No. 8, 2011, pp. 1046-1053.

[24] J. L. Chen, S. Godfrey, T. T. Ng, R. Moorthi, O. Liangos, R. Ruthazer, B. L. Jaber, A. S. Levey and C. CastanedaSceppa, "Effect of Intra-Dialytic, Low-Intensity Strength Training on Functional Capacity in Adult Haemodialysis Patients: A Randomized Pilot Trial," Nephrology Dialysis Transplantation, Vol. 25, No. 6, 2010, pp. 1936-1943. doi:10.1093/ndt/gfp739

[25] K. L. Johansen, P. L. Painter, G. K. Sakkas, P. Gordon, J. Doyle and T. Shubert, "Effects of Resistance Exercise Training and Nandrolone Decanoate on Body Composition and Muscle Function among Patients Who Receive Hemodialysis: A Randomized, Controlled Trial," Journal of the American Society of Nephrology, Vol. 17, No. 8, 2006, pp. 2307-2314. doi:10.1681/ASN.2006010034

[26] K. R. Wilund, E. J. Tomayko, P. T. Wu, H. Ryong Chung, S. Vallurupalli, B. Lakshminarayanan and B. Fernhall, "Intradialytic Exercise Training Reduces Oxidative Stress and Epicardial Fat: A Pilot Study," Nephrology Dialysis Transplantation, Vol. 25, No. 8, 2010, pp. 2695-2701. doi:10.1093/ndt/gfq106

[27] J. Dong, M. B. Sundell, L. B. Pupim, P. Wu, A. Shintani and T. A. Ikizler, "The Effect of Resistance Exercise to Augment Long-Term Benefits of Intradialytic Oral Nutritional Supplementation in Chronic Hemodialysis Patients," Journal of Renal Nutrition, Vol. 21, No. 2, 2011, pp. 149-159. doi:10.1053/j.jrn.2010.03.004

[28] S. Frey, A. R. Mir and M. Lucas, "Visceral Protein Status and Caloric Intake in Exercising versus Nonexercising Individuals with End-Stage Renal Disease," Journal of Renal Nutrition, Vol. 9, No. 2, 1999, pp. 71-77. doi:10.1016/S1051-2276(99)90003-1

[29] M. Reboredo Mde, V. Pinheiro Bdo, J. A. Neder, M. P. Avila, E. R. M. L. Araujo, A. F. de Mendonca, M. V. de Mello, A. C. Bainha, J. Dondici Filho and R. B. de Paula, "Effects of Aerobic Training during Hemodialysis on Heart Rate Variability and Left Ventricular Function in End-Stage Renal Disease Patients," Jornal Brasileiro de Nefrologia, Vol. 32, No. 4, 2010, pp. 367-373.

[30] R. Afshar, L. Shegarfy, N. Shavandi and S. Sanavi, "Effects of Aerobic Exercise and Resistance Training on Lipid Profiles and Inflammation Status in Patients on Maintenance Hemodialysis," Indian Journal of Nephrology, Vol. 20, No. 4, 2010, pp. 185-189. doi:10.4103/0971-4065.73442

[31] M. Daniilidis, E. Kouidi, E. Giagoudaki, A. Fleva, P. Nikolaides, A. Vasilaki, et al., "The Immune Response in Hemodialysis Patients Following Physical Training," Sport Sciences for Health, Vol. 1, 2004, pp. 11-16. doi:10.1007/s11332-004-0003-y

[32] A. Makhlough, E. Ilali, R. Mohseni and S. Shahmohammadi, "Effect of Intradialytic Aerobic Exercise on Serum Electrolytes Levels in Hemodialysis Patients," Iranian Journal of Kidney Diseases, Vol. 6, No. 2, 2012, pp. 119123. doi:10.1681/ASN.2007010009

[33] K. L. Johansen, "Exercise in the End-Stage Renal Disease Population," Journal of the American Society of $\mathrm{Ne}$ phrology, Vol. 18, No. 6, 2007, pp. 1845-1854.
[34] S. D. Anker, W. Steinborn and S. Strassburg, "Cardiac Cachexia," Annals of Medicine, Vol. 36, No. 7, 2004, pp. 518-529. doi:10.1080/07853890410017467

[35] M. Petraki, E. Kouidi, D. Grekas and A. Deligiannis, "Effects of Exercise Training during Hemodialysis on Cardiac Baroreflex Sensitivity," Clinical Nephrology, Vol. 70, No. 3, 2008, pp. 210-219.

[36] "KDIGO 2012 Clinical Practice Guideline for the Evaluation and Management of Chronic Kidney Disease," International Society of Nephrology, Vol. 3, No. 1, 2013, pp. 1-163.

[37] T. L. Parsons, E. B. Toffelmire and C. E. King-Van Vlack, "The Effect of an Exercise Program during Hemodialysis on Dialysis Efficacy, Blood Pressure and Quality of Life in End-Stage Renal Disease (ESRD) Patients," Clinical Nephrology, Vol. 61, No. 4, 2004, pp. 261-274.

[38] T. Akiba, N. Matsui, S. Shinohara, H. Fujiwara, T. Nomura and F. Marumo, "Effects of Recombinant Human Erythropoietin and Exercise Training on Exercise Capacity in Hemodialysis Patients," Artificial Organs, Vol. 19, No. 12, 1995, pp. 1262-1268. doi:10.1111/j.1525-1594.1995.tb02297.x

[39] V. S. Balakrishnan, M. Rao, V. Menon, P. L. Gordon, M. Pilichowska, F. Castaneda and C. Castaneda-Sceppa, "Resistance Training Increases Muscle Mitochondrial Biogenesis in Patients with Chronic Kidney Disease," Clinical Journal American Society Nephrology, Vol. 5, No. 6, 2010, pp. 996-1002. doi:10.2215/CJN.09141209

[40] R. M. Carney, B. Templeton, B. A. Hong, H. R. Harter, J. M. Hagberg, K. B. Schechtman and A. P. Goldberg, "Exercise Training Reduces Depression and Increases the Performance of Pleasant Activities in Hemodialysis Patients," Nephron Clinical Practice, Vol. 47, No. 3, 1987, pp. 194-198.

[41] C. Castaneda, P. L. Gordon, K. L. Uhlin, A. S. Levey, J. J. Kehayias, J. T. Dwyer, R. A. Fielding, R. Roubenoff and M. F. Singh, "Resistance Training to Counteract the Catabolism of a Low-Protein Diet in Patients with Chronic Renal Insufficiency. A Randomized, Controlled Trial," Annals of Internal Medicine, Vol. 135, No. 11, 2001, pp. 965-976.

[42] C. Castaneda, P. L. Gordon, R. C. Parker, K. L. Uhlin, R. Roubenoff and A. S. Levey, "Resistance Training to Reduce the Malnutrition-Inflammation Complex Syndrome of Chronic Kidney Disease," American Journal of Kidney Diseases, Vol. 43, No. 4, 2004, pp. 607-616. doi:10.1053/j.ajkd.2003.12.025

[43] Y. Chang, S. Y. Cheng, M. Lin, F. Y. Gau and Y. F. Chao, "The Effectiveness of Intradialytic Leg Ergometry Exercise for Improving Sedentary Life Style and Fatigue among Patients with Chronic Kidney Disease: A Randomized Clinical Trial," International Journal of Nursing Studies, Vol. 47, No. 11, 2010, pp. 1383-1388. doi:10.1016/j.ijnurstu.2010.05.002

[44] B. Cheema, H. Abas, B. Smith, A. O'Sullivan, M. Chan, A. Patwardhan, J. Kelly, A. Gillin, G. Pang, B. Lloyd and M. F. Singh, "Progressive Exercise for Anabolism in Kidney Disease (PEAK): A Randomized, Controlled Trial of Resistance Training during Hemodialysis," Journal of the American Society Nephrology, Vol. 18, No. 5, 
2007, pp. 1594-1601. doi:10.1681/ASN.2006121329

[45] B. Cheema, H. Abas, B. Smith, A. O'Sullivan, M. Chan, A. Patwardhan, J. Kelly, A. Gillin, G. Pang, B. Lloyd and M. Fiatarone Singh, "Randomized Controlled Trial of Intradialytic Resistance Training to Target Muscle Wasting in ESRD: The Progressive Exercise for Anabolism in Kidney Disease (PEAK) Study," American Journal of Kidney Diseases, Vol. 50, No. 4, 2007, pp. 574-584. doi:10.1053/j.ajkd.2007.07.005

[46] B. S. Cheema, H. Abas, B. C. Smith, A. J. O'Sullivan, M. Chan, A. Patwardhan, J. Kelly, A. Gillin, G. Pang, B. Lloyd, K. Berger, B. T. Baune and M. A. Fiatarone Singh, "Effect of Resistance Training during Hemodialysis on Circulating Cytokines: A Randomized Controlled Trial," European Journal of Applied Physiology, Vol. 111, No. 7, 2011, pp. 1437-1445. doi:10.1007/s00421-010-1763-5

[47] P. Y. Chen, Y. C. Huang, Y. H. Kao and J. Y. Chen, "Effects of an Exercise Program on Blood Biochemical Values and Exercise Stage of Chronic Kidney Disease Patients," Journal of Nursing Research, Vol. 18, No. 2, 2010, pp. 98-107. doi:10.1097/JNR.0b013e3181dda726

[48] S. S. Fitts, M. R. Guthrie and C. R. Blagg, "Exercise Coaching and Rehabilitation Counseling Improve Quality of Life for Predialysis and Dialysis Patients," Nephron Clinical Practice, Vol. 82, No. 2, 1999, pp. 115-121.

[49] M. Flesher, P. Woo, A. Chiu, A. Charlebois, D. E. Warburton and B. Leslie, "Self-Management and Biomedical Outcomes of a Cooking, and Exercise Program for Patients with Chronic Kidney Disease," Journal of Renal Nutrition, Vol. 21, No. 2, 2011, pp. 188-195. doi:10.1053/j.jrn.2010.03.009

[50] A. P. Goldberg, E. M. Geltman, J. R. Gavin III, R. M. Carney, J. M. Hagberg, J. A. Delmez, A. Naumovich, M. H. Oldfield and H. R. Harter, "Exercise Training Reduces Coronary Risk and Effectively Rehabilitates Hemodialysis Patients," Nephron Clinical Practice, Vol. 42, No. 4, 1986, pp. 311-316.

[51] H. R. Harter and A. P. Goldberg, "Endurance Exercise Training. An Effective Therapeutic Modality for Hemodialysis Patients," Medical Clinics of North America, Vol. 69, No. 1, 1985, pp. 159-175.

[52] S. A. Headley, M. J. Germain, C. M. Milch, M. P. Buchholz, M. A. Coughlin and L. S. Pescatello, "Immediate Blood Pressure-Lowering Effects of Aerobic Exercise among Patients with Chronic Kidney Disease," Nephrology (Carlton), Vol. 13, No. 7, 2008, pp. 601-606. doi:10.1111/j.1440-1797.2008.01030.x

[53] E. Konstantinidou, G. Koukouvou, E. Kouidi, A. Deligiannis and A. Tourkantonis, "Exercise Training in Patients with End-Stage Renal Disease on Hemodialysis: Comparison of Three Rehabilitation Programs," Journal of Rehabilitation Medicine, Vol. 34, No. 1, 2002, pp. 4045. doi:10.1080/165019702317242695

[54] D. J. Leehey, I. Moinuddin, J. P. Bast, S. Qureshi, C. S. Jelinek, C. Cooper, L. C. Edwards, B. M. Smith and E. G. Collins, "Aerobic Exercise in Obese Diabetic Patients with Chronic Kidney Disease: A Randomized and Controlled Pilot Study," Cardiovascular Diabetology, Vol. 8, 2009, p. 62.

[55] Y. Matsumoto, A. Furuta, S. Furuta, M. Miyajima, T. Sugino, K. Nagata and S. Sawada, "The Impact of PreDialytic Endurance Training on Nutritional Status and Quality of Life in Stable Hemodialysis Patients (Sawada Study)," Renal Failure, Vol. 29, No. 5, 2007, pp. 587-593. doi:10.1080/08860220701392157

[56] S. Molsted, I. Eidemak, H. T. Sorensen and J. H. Kristensen, "Five Months of Physical Exercise in Hemodialysis Patients: Effects on Aerobic Capacity, Physical Function and Self-Rated Health," Nephron Clinical Practice, Vol. 96, No. 3, 2004, pp. c76-c81. doi:10.1159/000076744

[57] S. Mustata, S. Groeneveld, W. Davidson, G. Ford, K. Kiland and B. Manns, "Effects of Exercise Training on Physical Impairment, Arterial Stiffness and Health-Related Quality of Life in Patients with Chronic Kidney Disease: A Pilot Study," International Urology and Nephrology, Vol. 43, No. 4, 2011, pp. 1133-1141. doi:10.1007/s11255-010-9823-7

[58] S. Ouzouni, E. Kouidi, A. Sioulis, D. Grekas and A. Deligiannis, "Effects of Intradialytic Exercise Training on Health-Related Quality of Life Indices in Haemodialysis Patients," Clinical Rehabilitation, Vol. 23, No. 1, 2009, pp. 53-63. doi:10.1177/0269215508096760

[59] P. L. Painter, L. Hector, K. Ray, L. Lynes, S. Dibble, S. M. Paul, S. L. Tomlanovich and N. L. Ascher, "A Randomized Trial of Exercise Training after Renal Transplantation," Transplantation, Vol. 74, No. 1, 2002, pp. 42-48. doi:10.1097/00007890-200207150-00008

[60] E. Segura-Orti, E. Kouidi and J. F. Lison, "Effect of Resistance Exercise during Hemodialysis on Physical Function and Quality of Life: Randomized Controlled Trial," Clinical Nephrology, Vol. 71, No. 5, 2009, pp. 527-537. 